\title{
Review: pimozide had effects on global functioning and mental state similar to typical antipsychotic drugs for schizophrenia
}

Sultana A, McMonagle T. Pimozide for schizophrenia or related psychoses. Cochrane Database Syst Rev 2000;3:latest

version 26 Sep 2000.

QUESTION: Is pimozide effective for improving symptoms in patients with schizophrenia or delusional disorder?

\section{Data sources}

Studies were identified by searching electronic databases, the Cochrane Library (to April 1999), references of relevant studies, and high yield journals and by contacting authors and manufacturers of pimozide.

\section{Study selection}

Studies were selected if they were randomised controlled trials that compared pimozide with placebo, no treatment, or another drug in people with schizophrenia or delusional disorder. Exclusion criteria included schizoaffective disorder, dementing illnesses, depression, and substance abuse.

\section{Data extraction}

Reviewers assessed the quality of study methods using the criteria in the Cochrane Collaboration Handbook and the Jadad scale. Data were extracted on methods, patients, drug regimens, and outcomes.

\section{Main results}

34 studies met the selection criteria. Most of the 1278 patients (mean age approximately $43 \mathrm{y}$ ) had schizophrenia, and none had delusional disorder. The mean dose of pimozide (16 studies) was $7.5 \mathrm{mg} /$ day (range $1-70 \mathrm{mg} / \mathrm{d}$ in 26 studies). Fewer patients in the pimozide group than in the placebo group had clinical relapses at 6 months to 1 year (3 studies, 103 patients; table). At 3-12 months, fewer patients in the pimozide group than in the placebo group withdrew for any reason (table). 29 studies compared pimozide with oral neuroleptic drugs; 5 studies involved a long acting depot preparation (fluphenazine decanoate), and no studies involved atypical antipsychotic drugs. Pimozide and oral neuroleptic drugs had similar results for global state, mental state, or leaving the study early, and there were no consistent differences in adverse events, including deaths.

\section{Conclusions}

Pimozide led to results for global and mental states similar to typical neuroleptic drugs in patients with schizophrenia. No data from randomised controlled trials exist for the use of pimozide in delusional disorder.
Pimozide (pim) v placebo for schizophrenia or related psychoses*

\begin{tabular}{|c|c|c|c|c|c|}
\hline \multirow[b]{2}{*}{ Outcomes } & \multirow{2}{*}{$\begin{array}{l}\text { No of } \\
\text { studies }\end{array}$} & \multicolumn{2}{|c|}{$\begin{array}{l}\text { Weighted event } \\
\text { rates }\end{array}$} & \multirow[b]{2}{*}{ RRR $(95 \%$ Cl) } & \multirow[b]{2}{*}{ NNT (Cl) } \\
\hline & & Pim & Placebo & & \\
\hline $\begin{array}{l}\text { Clinical diagnosis of } \\
\text { relapse at } 6-12 \text { months }\end{array}$ & 3 & $34 \%$ & $67 \%$ & $41 \%$ (22 to 56 ) & $4(2$ to 13$)$ \\
\hline $\begin{array}{l}\text { Withdrawal for any reason } \\
\text { at } 3-12 \text { months }\end{array}$ & 3 & $42 \%$ & $67 \%$ & $35 \%$ (2 to 57 ) & 5 (3 to 82$)$ \\
\hline
\end{tabular}

\section{COMMENTARY}

Pimozide is a high potency antipsychotic medication which has been used in many countries since the 1970s for the treatment of schizophrenia and other psychoses. In the US, it was licensed in the past decade as an "orphan drug" for the treatment of Tourette's syndrome.

Sultana and McMonagle have identified randomised controlled trials of pimozide for the treatment of schizophrenia. Not surprisingly, pimozide was found to be more effective than placebo for preventing relapse and was similar to other typical antipsychotic drugs in efficacy and side effect profile.

Several unanswered questions remain. It has been claimed that pimozide is more effective than other typical antipsychotic drugs for treating negative symptoms of schizophrenia. ${ }^{1}$ None of the studies included in the review specifically reported on negative symptoms as an outcome, so the review was unable to support or refute this claim. In addition, the efficacy of pimozide relative to the newer atypical antipsychotic drugs is unknown because no trial comparing pimozide with an atypical antipsychotic drug was identified.

The safety of pimozide has been questioned after case reports of arrhythmias, prolongation of the QTc (QT corrected for heart rate) interval, and sudden death. ${ }^{2}$ This review found no differences in deaths or cardiac symptoms between pimozide and other antipsychotic drugs. Few useful ECG data were reported, so recommendations regarding ECG monitoring could not be derived.

Lastly, none of the clinical trials involved patients with delusional disorder. Although pimozide is frequently recommended as the first line drug in the treatment of delusional disorder, ${ }^{3}$ this is based largely on case reports. ${ }^{4}$ Clinical trials comparing pimozide with other antipsychotics in the treatment of delusional disorder are clearly warranted.

Gregory E Gray, MD, PhD Charles $R$ Drew University of Medicine and Science Los Angeles, California, USA

1 Opler LA, Feinberg SS. The role of pimozide in clinical psychiatry: a review. J Clin Psychiatry 1991;52:221-33.

2 Royal College of Psychiatrists' Psychopharmacology SubGroup. The association between antipsychotic drugs and sudden death. Council Report CR 57. London: Royal College of Psychiatrists, 1997.

3 Csernansky JG. Delusional disorder. In: Dunner DL, editor Current psychiatric therapy. 2nd edition. Philadelphia, PA: WB Saunders, 1997.

4 Munro A, Mok H. An overview of treatment in paranoia delusional disorder. Can J Psychiatry 1995;40:616-22.
Source of funding: no external funding.

For correspondence: Dr A Sultana, Specialist Registrar in Psychiatry, St Andrews Hospital, Addenbrooks NHS Trust, Billing Road, Northampton, Northamptonshire NN1 5DG, UK. Fax +44 (0)1223 218675. 